\title{
Multiple Linear Regression Analysis on Factors Affecting Coffee Production in Bench-Shako Zone: In Case of Mizan-Aman District, Southwest Ethiopia
}

\author{
Alemu Bekele*, Tewabe Guadie \\ Department of Statistics, College of Natural and Computational Science, Mizan-Tepi University, Tepi, Ethiopia \\ Email address: \\ abestat10@gmail.com (A. Bekele), nwaqagad@gmail.com (T. Guadie) \\ ${ }^{*}$ Corresponding author
}

\section{To cite this article:}

Alemu Bekele, Tewabe Guadie. Multiple Linear Regression Analysis on Factors Affecting Coffee Production in Bench-Shako Zone: In Case of Mizan-Aman District, Southwest Ethiopia. Advances in Bioscience and Bioengineering. Vol. 8, No. 2, 2020, pp. 24-30.

doi: $10.11648 /$ j.abb.20200802.13

Received: June 12, 2020; Accepted: June 24, 2020; Published: August 10, 2020

\begin{abstract}
Coffee is the major source of income for smallholder farmers and it is leading export crop for Ethiopia. Identifying factors affecting Coffee production is very important to improve the production coffee in the country. This paper is focused on the factors that affect the production of coffee in Mizan-Aman district. Using simple random sampling 124 Coffee farmers were selected in Mizan-Aman district. The data was gathered by prepared questionnaires and analyzed by IBM SPSS version 20. From the total of 124 farmers $70(56.5 \%)$ are males and $54(43.5 \%)$ are females and the peak age of the coffee producer is 59 years, while the least age is 26 years. The experience of coffee producer was estimated on average 8 years and five months. Multiple linear regressions is made and the regression results revealed that factors such as education level, types of coffee, farmers total income and farm size are determinants of coffee production. Therefore the conclusion is that the farmers should develop their education level to maximize their coffee production and coffee producing farmers have to use different types of coffee seeds to maximize their production. Not only these but also farmer's income and farm size are very important factors that increase coffee production. Generally from the paper, coffee production will improved if the farmers and agricultural workers incorporate the determinants identified by this study.
\end{abstract}

Keywords: Coffee Production, Multiple Linear Regression, Factors of Coffee Production

\section{Introduction}

Coffee is the worldwide preferred drink and the most traded goods next to oil internationally in both value and size [1]. It is a significant source of income to numerous developing countries in Africa, Asia and Latin America [2]. Ethiopia is one of those countries and which is the largest producer of coffee and ranks fifth in the world and first in Africa by annual coffee production. It is the origin of coffee Arabica [1]. For the past three to four decades, coffee has been and remains the leading cash crop and major export commodity of the country [1]. Ethiopia is the largest coffee consumer in Africa and second top consumer after Brazil among coffee producing countries [3]. Ethiopia was earned 35\% foreign exchange from coffee seals in 2015_2016. Coffee is also a principal means of income for the rural population and an unavoidable hot and cold drink in daily menu in the country [4]. In Ethiopia, coffee is produced in forest, semi-forest and garden plantation methods.

The most Coffee growing regions in Ethiopia are Oromia and Southern Nations Nationalities and People's Region (SNNPR). In the south west; Jimma, Kaffa, Maji, Mizan-Aman and Tepi are among the major coffee producing areas [5]. In Bench Maji zone there are large difference in coffee production between districts such as Semen Bench, Debub Bench, Sheko, Guraferda, SheyBench, M. Golida, Maji, Beru and Mizan_Aman districts. The least amount of coffee produced and reported from Mizan-Aman district in 2017 [4]. Hence, Mizan-Aman district was selected to conduct research on factors affect coffee production to identify determinants.

In Africa, the common factors agricultural crop output was 
inputs used in production. These input factors were farming labor, capital, land, chemical fertilizers, improved seeds, irrigation, agrochemicals, extension, and service sector outputs [6]. Hence, these factors were alike for coffee production; they were incorporated to the study except service factors. Additionally, the study that done on factors affecting coffee quality viewed that species or variety of coffee, environmental conditions, agronomical practices, processing and storage conditions [7]. Another study that done from West Hararghe Zone, Daro Labu district that based on factors affecting coffee productivity with 120 coffee producers and analyzed by Cobb-Douglas production function revealed that; fertilizer, coffee farm size, family labor, coffee farming experience, land allocated for Khat were significant variables [8] while another paper reported poor adoption [9]. A similar study identified factors leads to low productivity of coffee as the shortage of farm land [4]. Also another study which conducted in four zones of SNNPR reported that insect pests, weed species, vertebrate animals, recurrent drought, frost, fluctuating rainfall pattern, high humidity, high temperature, low moisture, hail, storm, wind and reduced soil fertility were among factors affecting coffee production [10].

Even though several papers have been done on the factors of coffee production, most of these researches use qualitative data that didn't "had statistically confirmed results on model diagnostic [2, 7, 8, 10]." The farmers were not greatly benefited from coffee they produce due to various determinants in the Bench-Maji zone and the income from production of coffee in that area is not fulfilling the needs of a lot of farmers in the district [4]. The main objective of the study is to identify the major factors that affecting coffee production in Mizan-Aman and fit statistically valid model. The purpose of the study is benefit to all coffee producing farmers these didn't know how to improve their production. Also it helps agricultural workers to give full aid for the farmers that produce low coffee.

Simple linear regression was used to regresses the relationship between coffee production and land area in Bench-Maji zone [4] and it identified only land size is significant factor. But in reality the land size is not the only factor. Therefore, Multiple Linear Regression was applied to identify more determinants of coffee production in Mizan-Aman district.

\section{Methods}

\subsection{Data Source}

The study conducted in South West Ethiopia, Bench_Shako Zone, Mizan_Aman district which is located $562 \mathrm{~km}$ away from Addis Ababa Capital City of Ethiopia. The major economic activities of the peoples in this area are producing crops such as maize, wheat, coffee, banana, inset, ginger, and the others. From these crops ginger and coffee are used as cash crop while wheat, maize and inset are used for household consumption purpose. The area has well suitable climatic and geographic condition which is easily adapted by every human being as well as plants and animals. The farmers of these Mizan_Aman produce coffee for financial purpose and they supplied it to local merchants. The local merchants also buy total quantity of output which is supplied by farmers and further send it to those merchants who are found in Addis Ababa.

\subsection{Data Collection}

\subsubsection{Study Design}

A cross-sectional study design was carried out on farmers producing coffee in Mizan-Aman district starting from June 2018.

A simple random sampling was used to select 124 farmers and primary data was collected from those farmers by using structured questionnaire and interviews.

The data was analyzed by IBM SPSS version 20 software.

\subsubsection{Variables of the Study}

The dependent variable in this study was coffee yield in quintal in 2010 E.C from Mizan-Aman woreda. The independent variables for this study were socio-economic factors that listed in Table 1.

Table 1. List and Description of Variables used in Coffee Production in data.

\begin{tabular}{ll}
\hline Variables & Category/Codes \\
\hline Sex & $0=$ Male, 1=Female \\
Education level & 0=Illiterate, 1=Primary school \\
2=Secondary School, 3=Above secondary School \\
Fertilizer & $0=$ Used, 1=Never Used \\
Irrigation & $0=$ Used, 1=Never Used \\
Coffee pruning & $0=$ Yes, 1=No \\
Tree shade & $0=$ Yes 1=No \\
Types of coffee & $0=$ Forest, 1=Garden, 2= Other \\
Farm Size & Land size in hectare \\
Income & In quintal \\
Age of & Years \\
\hline
\end{tabular}

\subsection{Data Analysis Methods}

\subsubsection{Linear Regression}

Linear regression analysis is a statistical method that used to estimate the relationship between one or more independent variables and a single dependent variable [11]. Accordingly this paper used Multiple Linear Regression to determine significant factors from potential explanatory variables listed in Table 1 .

The general form of a multiple linear regression model is given by:

$$
Y=\beta_{0}+\beta_{1} X_{1}+\beta_{2} X_{2}+\cdots+\beta_{k} X_{k}+\varepsilon_{i}
$$

Where, $\mathrm{Y}=$ Coffee produced in quintal

$\beta_{0}$ is the intercept and $\beta_{1}, \beta_{2}, \ldots, \beta_{\mathrm{k}}$ are coefficients of the variable $\mathrm{X}_{1}, \mathrm{X}_{2, \ldots}, \mathrm{X}_{\mathrm{k}}$ are independent variables and $\varepsilon_{\mathrm{i}}$ error term.

\subsubsection{Estimation of Parameters}

The Maximum Likelihood method is used to estimate parameters of regression model [12]. Test of overall linear 
regressions model was made by ANOVA table given in table

2.

Table 2. Analysis of Variance table that used in Regression model overall test.

\begin{tabular}{lllll}
\hline Sources & Sum square & D.f & Mean of Square & F - Statistic \\
\hline Between Error & SSR & $k-1$ & MSR & \\
Within Error & SSE & $n-k$ & MSE & F=MSR/MSE \\
Total & SST & $n-1$ & MST & \\
\hline
\end{tabular}

Where: $\mathrm{MSR}=$ mean square regression, $\mathrm{MSE}=$ mean square error and $\mathrm{k}=$ number of predictors.

Hypothesis:

Null: $H_{O}=\beta_{1} x_{1}=\beta_{2} x_{2}=\ldots=\beta_{7} x_{7}=0$

Alternative: $H_{1}=\beta_{i j} \neq 0$

Test statistic: We can test by using P-value of the estimate.

Decision: If the P-value is less than the $\alpha$ level of significance, then rejects the null hypothesis and the regression model is good.

\subsubsection{Coefficient of Determination $\left(R^{2}\right)$}

Coefficient of determination is measure of the contribution of independent variables in the model. It is calculated by:

$$
\mathrm{R}^{2}=\frac{\mathrm{SSR}}{\mathrm{SST}}
$$

Where: $S S R=$ sum square regression.

$S S T=$ sum square total.

\subsection{Model Diagnostics}

The assumptions of linear regressions must be checked to accept the results of regression models.

\subsubsection{Homoscedasticity and Normality}

Plotting the standardized residuals against time order are not only helpful to study whether a linear regression function is appropriate but also to examine the variance of the error term is constant. Normality is tested by histogram and $p-p$ plot.

\subsubsection{Multi-Collinearity}

The decision is based on variance inflection factor (VIF). If
VIF valus is less than 10 , then multi collinearity between independent variables is tolerable but if VIF value is greater than 10 then multi Collinearity is a problem.

\subsubsection{Linearity}

Linearity indicates that the relationship between dependent and independent variable should be linear. It is tested by $p-p$ plot.

\section{Results}

\subsection{Descriptive Results}

From table 3 , the average age of coffee producer farmer is about 42 years and 3 months while the minimum and the maximum age is 26 and 59 years respectively. The experience of farmers on coffee production was estimated on average 8 years and 5 months, but the uppermost year of experience of coffee production is 23 years and the minimum year of experience of coffee production is 2 years. The farmer's income per year was estimated at an average of 69644.9194 birr. The highest farmer's income per year is 110000.00 birr and the minimum farmer's income per year is 45000.00 birr. The farm size in hectare was estimated at an average 5.7097 hectare. The highest farm size is 10.00 and the minimum farm size is 2.00 hectare. The average amount of coffee produced per year is 58.7339 quintal. The highest amount of coffee produced per year is 100.00 quintal and the minimum amount of coffee per year is 25.00 quintal.

Table 3. Results Obtained from Descriptive Statistics on Quantitative Variables Using Coffee Production in Mizan-Aman, 2018.

\begin{tabular}{lllll}
\hline Variables & Observation & Minimum & Maximum & Mean (Average) \\
\hline Age (in year) & 124 & 26.00 & 59.00 & 42.3065 \\
Experience (year) & 124 & 2.00 & 23.00 & 8.5806 \\
Income (in birr) & 124 & 45000.00 & 110000.00 & 69644.9194 \\
Coffee (in quintal) & 124 & 25.00 & 100.00 & 58.7339 \\
Farm size (hectare) & 124 & 2.00 & 10.00 & 5.7097 \\
\hline
\end{tabular}

From table 4 , it is revealed that $70(56.5 \%)$ are male farmers and $54(43.5 \%)$ are female farmers. Male farmers produce averagely 61 quintal of coffee production and female farmers produce averagely 55.7963 quintal of coffee. According to education level; 65 (52.4\%) of respondents were cannot read and write and they produce averagely 55.2 quintal of coffee, $35(28.2 \%)$ of the respondents are primary school and they produce averagely 62.2587 quintal of coffee, $11(8.9 \%)$ of the respondents are secondary school attended and they produce averagely 68.6364 quintal of coffee, $13(10.5 \%)$ of the respondents are above secondary education level and they produce averagely 58.4615 quintal of coffee.

According fertilize use; 73 (58.9\%) of respondents' used fertilizer and they produce averagely 59.6956 quintal while, $51(41.1 \%)$ of respondents not used fertilizer and they produce averagely 57.3529 quintal of coffee. Similarly, 76 (61.3\%) of the respondents whose use of irrigation for coffee tree produced averagely 61.8421 quintal of coffee while, 48 $(38.7 \%)$ of respondents are no used of irrigation for coffee trees and they produce averagely 53.8125 quintal of coffee 
production. In coffee pruning practice; 70 (56.5\%) of the respondents are participate Coffee pruning practice and they produce averagely 59.4 quintal of coffee while, 54 (43.5\%) of respondents are not participate Coffee pruning practice and they produce averagely 57.8704 quintal of coffee.

In case of tree shadow, $47(37.9 \%)$ of the farmers were used tree shadow to produce averagely 57.1915 quintal of coffee but $77(62.1 \%)$ of the farmers were not used shadow tree to produce averagely 59.6753 quintal of coffee. In the same way, $40(32.3 \%)$ of the respondents were used forest coffee type and produced averagely 57.075 quintal of coffee, 49 (39.5\%) of the respondents were used Garden coffee and produced averagely 59.0816 quintal of coffee and 35 (28.2\%) of the respondents were used other type of coffee and produced averagely 60.1429 quintal of coffee.

Table 4. Results obtained from descriptive statistics, on categorical variables with average coffee production using Coffee production data in Mizan-Aman, 2018.

\begin{tabular}{|c|c|c|c|c|}
\hline Variables & Category & Count & Average coffee produce in quintal & Percent (\%) \\
\hline \multirow{2}{*}{ Sex } & Male & 70 & 61 & $56.5 \%$ \\
\hline & Female & 54 & 55.7963 & $43.5 \%$ \\
\hline \multirow{4}{*}{ Educational level } & Illiterate & 65 & 55.2 & $52.4 \%$ \\
\hline & Primary & 35 & 62.2587 & $28.2 \%$ \\
\hline & Secondary & 11 & 68.6364 & $8.9 \%$ \\
\hline & Above secondary & 13 & 58.4615 & $10.5 \%$ \\
\hline Fertilizer used & No & 51 & 57.3529 & $41.1 \%$ \\
\hline \multirow{2}{*}{ Irrigation use } & Yes & 76 & 61.8421 & $61.3 \%$ \\
\hline & No & 48 & 53.8125 & $38.7 \%$ \\
\hline \multirow{2}{*}{ Pruning practices } & Yes & 70 & 59.4 & $56.5 \%$ \\
\hline & No & 54 & 57.8704 & $43.5 \%$ \\
\hline \multirow[b]{2}{*}{ Tree shade } & Yes & 47 & 57.1915 & $37.9 \%$ \\
\hline & No & 77 & 59.6753 & $62.1 \%$ \\
\hline \multirow[t]{2}{*}{ Types of coffee } & Garden & 49 & 59.0816 & $39.5 \%$ \\
\hline & Others & 35 & 60.1429 & $28.2 \%$ \\
\hline
\end{tabular}

\subsection{Results on Multiple Linear Regression}

In Table 5 , since p-value $\left(.000^{\mathrm{b}}\right)$ is less than level of significance 0.05 , the overall regression model is significant.
That means at least one regression parameter is different from null and at least one of the predictor variable is determinant for coffee production.

Table 5. Results obtained from Analysis of Variance, using Coffee production data in Mizan-Aman 2018.

\begin{tabular}{lllll}
\hline sources & Sum of Squares & Df & Mean Square & F \\
\hline Regression & 33240.930 & 11 & 3021.903 & 212.95 \\
Residual & 1589.287 & 112 & 14.190 & \\
Total & 34830.218 & 123 & & \\
\hline
\end{tabular}

From table 6, a coefficient of determination $\left(\mathrm{R}^{2}\right)=0.954$ indicated that $95.4 \%$ of variation in the coffee production is explained by the predictors listed in table 1 that fitted to the model. Similarly, $\mathrm{R}^{2}$ (Adjusted) $=0.95$; implies that $95 \%$ of the variation of amount of coffee production is explained by the regression model.

Table 6. Results Obtained From Coefficient of Determination, Using Coffee Production Data in Mizan-Aman 2018.

\begin{tabular}{lll}
\hline R Square & Adjusted Square & Std. Erro \\
\hline 0.954 & 0.950 & 3.76697 \\
\hline
\end{tabular}

The fitted regression model is given:

$$
\begin{gathered}
\hat{Y}=\hat{\beta} o+\hat{\beta}_{1} X_{1} 1+\hat{\beta}_{2} X_{2}+\widehat{\beta_{3}} X_{3}+\widehat{\beta_{4}} X_{4} \\
\hat{Y}=-1.030+.903 X_{1}-1.104 X_{2}+.001 X_{3}+5.663 X_{4}
\end{gathered}
$$

Where $\widehat{\mathrm{Y}}=$ amount coffee production in the 2018 in quintal;
$\mathrm{X}_{1}=$ education level of coffee producer; $\mathrm{X}_{2}=$ types of coffee produced; $X_{3}=$ farmer income from coffee; and $X_{4}=$ farm size in hectare

From table 7, covariates like education level of farmer, type of coffee produced, farmer total income and farm size, each has $\mathrm{p}$-value $0.021,0.03,0.000,0.000$ respectively which is less than level of significance 0.05 . Thus, education levels, types of coffee, farmer income and farm size are statistically significant factors of coffee production.

In contrast, sex, age of farmer, fertilizer use, coffee pruning practice, use of irrigation and trees shade each has no significant effect on coffee production, since their $p$-value is greater than level of significance $5 \%$.

More specifically, intercept $\left(\widehat{\beta_{0}}\right)=(-) 1.03$ is the estimated average coffee produced when any predictor variable is not considered in the model. The negative sign indicates that without these factors production is decline. Education level coefficient $\widehat{\beta_{1}}=0.903$, implies that when education level of 
coffee producer is increased by one step, then coffee production is increased by 0.093 quintal. Coffee type slope $\widehat{\beta_{2}}$ $=-1.104$, indicates that when the types of coffee is forest, then the coffee production is decreased by 1.104 keeping all other variables as constant. Coefficient on income is $\widehat{\beta_{3}}=0.001$, shows that when an income of coffee producer is increased by one birr, then the coffee production is increased by 0.001 quintal if all other variable are fixed. Lastly farm size (area) $\widehat{\beta_{4}}=5.663$, point out that when farm size of coffee is increased by one hectare, then the coffee production is increased by 5.663 quintal if taking all other variables as a constant.

Table 7. Results obtained from fitted regression model and Fitted Regression Coefficients using Coffee production data in Mizan-Aman 2018.

\begin{tabular}{|c|c|c|c|c|c|}
\hline \multirow{2}{*}{ Variables } & \multicolumn{2}{|c|}{ Unstandardized Coefficients } & \multirow{2}{*}{$\begin{array}{l}\text { Standardized Coefficients } \\
\text { Beta }\end{array}$} & \multirow{2}{*}{ T. test } & \multirow{2}{*}{ Sig. } \\
\hline & B & Std. Error & & & \\
\hline (Constant) & -1.030 & 2.782 & & -.370 & .712 \\
\hline Farmer Sex & .227 & .721 & .007 & .316 & .753 \\
\hline Farmer Age & -.031 & .046 & -.016 & -.686 & .494 \\
\hline Education level & .903 & .385 & .053 & 2.346 & $.021 *$ \\
\hline Coffee Type & -1.104 & .523 & -.051 & -2.110 & $.037^{*}$ \\
\hline Farmer income & .0001 & .000011 & .412 & 8.565 & $.000 *$ \\
\hline Farm size & 5.663 & .457 & .591 & 12.387 & $.000^{*}$ \\
\hline Fertilizer use & -.634 & .775 & -.019 & -.819 & .415 \\
\hline Coffee pruning & -.494 & .768 & -.015 & -.644 & .521 \\
\hline Irrigation use & .308 & .829 & .009 & .371 & .712 \\
\hline Shade Tree & -.230 & .758 & -.007 & -.303 & .762 \\
\hline
\end{tabular}

\subsection{Model Adequacy Check}

Linearity:

Normal Probability plot is used to check the relationship between Coffee production and independent variables. "Figure 1", show that p-p plot graph indicates that all observations are lies approach to the straight line fitted. This implies that the relationship between coffee production and predictors are approximately linear.

\section{Normal P-P Plot of Regression Standardized Residual}

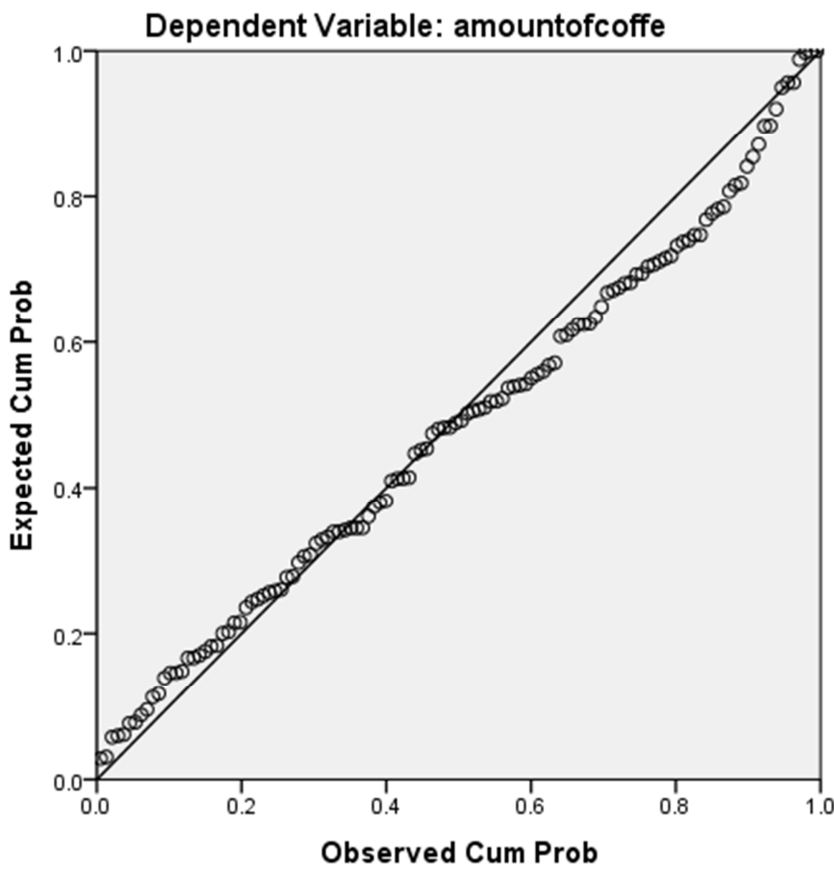

Figure 1. Normal p-p plot of standardized residual of Coffee production.

Normality:
Normality is checked by graphical method using histogram of residual. The normality assumption is approximately fitted on "Figure 2" because the histogram of residuals of the coffee production has bell shape and unimodal.

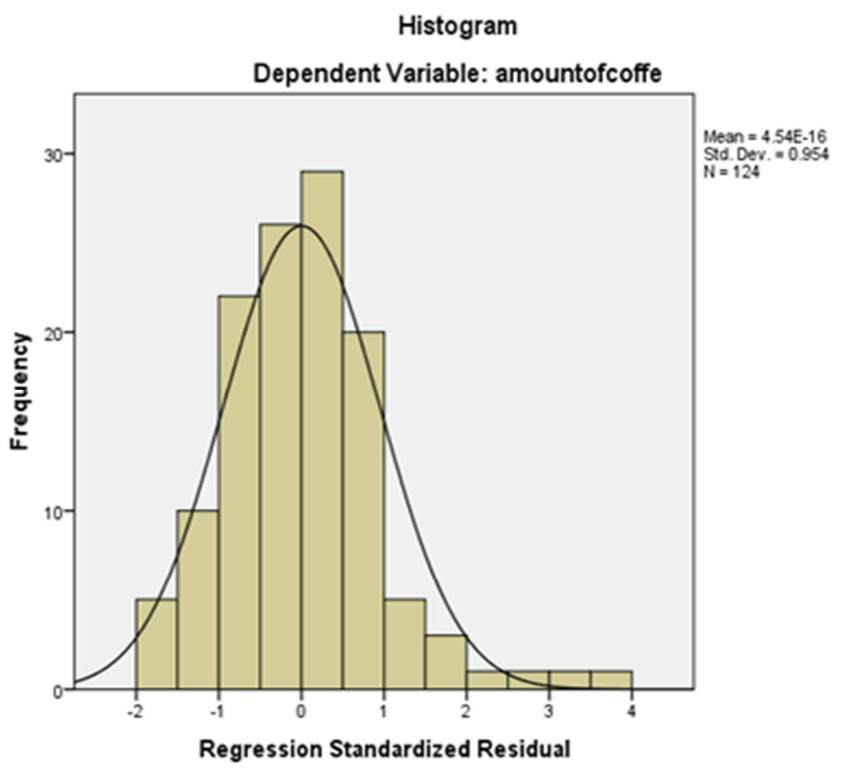

Figure 2. Histogram of Residual regression fitted on Coffee production.

Homoscedasticity:

Homoscedasticity is checked by the scatter plot of standard fitted values against standard residuals. The scatter plot of standard fitted values versus standard residual on "Figure 3" had no systematic pattern. This indicates that the data has somewhat constant variance.

Multicollinearity

As the rule of thumb, if the VIF of a variable exceeds 10 , that variable is said to be highly collinear. On Table 8, VIF of all independent variables less than 10, it indicates that absence 
of strong multicollinearity in all predictors.

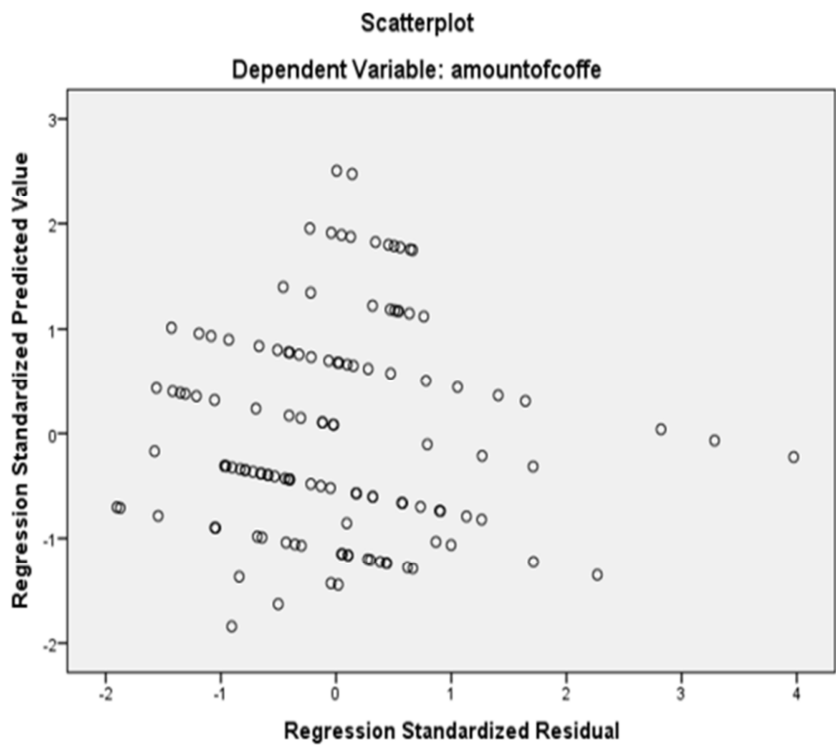

Figure 3. Scatter plot of Standardized Residual and Standardized Predicted value on Coffee production data in Mizan-Aman.

Table 8. Results obtained from Variance influence factor using Coffee production data in Mizan-Aman 2018.

\begin{tabular}{lll}
\hline \multirow{2}{*}{ Variables } & \multicolumn{2}{l}{ Collinearity Statistics } \\
\cline { 2 - 3 } & Tolerance & VIF \\
\hline Sex & .897 & 1.115 \\
Age & .777 & 1.287 \\
Education level & .788 & 1.270 \\
Type of coffee & .693 & 1.443 \\
Experience in Year & .727 & 1.376 \\
Farmer income in year & .176 & 5.681 \\
Farm size & .179 & 5.591 \\
Fertilizer use & .787 & 1.270 \\
pruning practice & .790 & 1.266 \\
Irrigation use & .701 & 1.426 \\
Tree shade & .845 & 1.183 \\
\hline
\end{tabular}

\section{Discussion and Conclusion}

\subsection{Discussion}

The main objective of this paper is to identify determinants of coffee production in Mizan_Aman district. Increasing coffee production is plan at the producer level [14]. A Multiple Linear Regression is used to analysis the data because the dependent variable is quantitative and there are several explanatory variables. In line, Simple Linear Regression was used in Bench-Maji zone to see the relationship between coffee production and land area [4]. On the other hand, multiple linear regression is fitted in this study and identified more significant factors of coffee production; education level, types of coffee, farmer income and farm size each has influence on coffee production. In contrast Ethiopian Coffee Science report; Mulching, Irrigation, Tree shade management and Pruning are factors of coffee production [5]. But neither these factors are supported in the paper. In opposition, variables like sex, age of farmer, fertilizer used, coffee pruning practice, use of irrigation and coffee shade trees have no enough evidence to support. This may be, because of the study in different area, and different population. The area of the study has fertile soil and humidity.

In another study, factors affecting coffee productivity that analyzed Cobb-Douglas function are fertilizer, coffee farm size, family labor, coffee farming experience, land allocated for Khat [8] and recommended to do more research on fertilizer [7]. The fertilizer is significant to coffee productivity in West Hararghe zone [8]. But fertilizer is not significant because of fertility of the soil in the area. The coffee price was reported as the factor [13]. The study by [10] identified that insect pests, weed species, vertebrate animals, recurrent drought, frost, fluctuating rainfall pattern, high humidity, high temperature, low moisture, hail, storm, wind and reduced soil fertility were among factors affecting coffee production. But most of these factors are qualitative and not statistically confirmed in that paper. However in this study most of these factors are fixed in the study area (temperature, humidity). The farmers were not used pest acids and weed acids. The purposes of this paper over all others studied were that the results were statistically confirmed and more factors were identified. The education of the farmers and type of coffee are the only confirmed factors under this study. Coffee farmers had inadequate land to produce coffee in line with $[4,16]$. The shortage of land is becoming more and more austere as growing population.

\subsection{Conclusion}

The main objective of this study is to identify factors coffee production in Mizan-Aman district. Multiple linear Regression method was applied to analyze the data with goodness of fit $95.4 \%$. This indicates that, about $95 \%$ factors coffee production was identified by the model.

The result from multiple linear regression revealed that education level of farmer, type of coffee cultivated, farmer income and farm size were statistically significant factors of coffee production. In generally to maximize the coffee production the farmers must; develop their education level by training, use different types of coffee or enterprise seed, invest more income, and cultivate more land. The agricultural expertise must consider the factors identified and help farmers to improve their coffee production.

Our research contributes to a growing number and quality of coffee production since it identified problems of farmers that producing coffee for markets because increasing coffee production is plan at the producer level. Support the farming community even under very poor living conditions in finance and land is suggested for administrations to improve production of coffee.

\section{Acknowledgements}

The authors would like to thanks Bench - Shako, Mizan-Aman administers because they had permitted to do this study. We have also great thanks to Mizan-Tepi University for Material Support. 


\section{References}

[1] Worako, T. K. Van Schalkwyk, H. D. Alemu, Z. G. and Ayele, G. (2008). Producer price and price transmission in a deregulated Ethiopian coffee market. Agrekon, vol. 47, no. 4, pp. $492-508$.

[2] Ameyu, M. A. (2017). Influence of harvesting and postharvest processing methods on the quality of Arabica coffee (Coffea arabica L.) in Eastern Ethiopia, no. March, 2017, doi: 10.5897/ISABB-JFAS2016.0051.

[3] Petit, N. (2007). Ethiopia' s Coffee Sector : A Bitter or Better Future?,"vol. 7, no. 2, pp. 225-263.

[4] Kaur R. and Melerasha, P. A. (2018). Impact of Size of an area on Coffee Production in Bench Maji, Ethiopia," vol. 6, no. 1, pp. 2017-2020.

[5] Mendesil, E. Berecha, G. Weldemichael, G. Belachew, K. and Kufa, T. (2017). Proceedings of Ethiopian Coffee Science Society (ECSS) Inaugural Conference Held on 7-8 April 2017, Jimma, Ethiopia," Jimma.

[6] Bachewe, F. N. Berhane, G. Minten, B. and Taffesse, A. S. (2017). Agricultural Transformation in Africa? Assessing the Evidence in Ethiopia, vol. xx.

[7] Belay, S. Mideksa, D. Gebrezgiabher S., Seifu, W. (2016). Factors Affecting Coffee (Coffea Arabica L.) Quality In Ehtiopia : A Review., vol. 4, no. 1, pp. 22-28.

[8] Temesgen, A. Tufa, A. (2017). Analysis of Coffee Farm Productivity in Darolabu District," vol. 2, no. 4, pp. 158-161, doi: 10.11648/j.ajere.20170204.12.

[9] Abdurahman, T. (2014). Determinants for the Adoption of Coffee Production Technologies; The Case of Small Holder Farmers in Mesela Woreda, Oromia National Regional State, Ethiopia. Indira Gandhi National Open University, M. A. Thesis.

[10] Tadesse, T. Tesfaye, B. and Abera, G. (2020). Coffee production constraints and opportunities at major growing districts of southern Ethiopia. Cogent Food Agric., vol. 6, no. 1, doi: 10.1080/23311932.2020.1741982.

[11] Dupont W. D. (2009). Statistical modeling for Biomedical Researchers, Second. New York: CAMBRIGE University.

[12] Lyman Ott M, (2001). An Introduction to Statistical Methods and Data Analysis Fifth Edition, 5th ed. Duxbury.

[13] Legese N., (2013). Performance Evaluation of Coffee Marketing Cooperatives Union: the case of Chercher Oda Bulttom Farmers ' Cooperatives Union West Harerghe Zone, Oromia Region, Ethiopia, Mekelle University. Thesis.

[14] Kelly, W. And Moira, L. A. (2008). Context and contingency: the coffee crisis for conventional small-scale coffee farmers in Brazil. The Geographical Journal, Vol. 174, No. 3, September 2008, pp. 223-234.

[15] Douglas C. Montogomery, E. A. P., \& Vining, G. (2013). Introduction to Linear Regression Analysis. In Вестник Казнму: Vol. №3 (fifth). Wiley.

[16] Fethi, O. Venugopal, K. Guday, A. M. Haimanote, B. A. (2016). An Assessment of Factors Influencing the Market Performance of Coffee Farmers' Cooperatives in Melka Balo Woreda: The Case of Kurtu Cooperatives Society, Ethiopia, IJRIAS, Volume I, Issue II, ISSN 2454-6194. 